\title{
Dental charity work - does it really help?
}

More than 70\% of the world's population, mainly those living in low- and middle-income countries, have little or no access to oral health care. Although oral health is recognised as a basic human right, the lack of appropriate and affordable oral care to more than four billion people worldwide has not to date resulted in a massive increase in political activity nor financial resources to address the problem.

One seemingly reasonable way to begin to address this problem is for dentists to use their skills overseas in the name of charity and of giving something back. Indeed, there are many from the high-income world who are prepared to volunteer to work in a low socio-economic community for a limited period. Their motivations in volunteering may vary but in most cases they are rooted in the recognition of need and the desire to help. Frequently they seek guidance from non-governmental organisations (NGOs) who send volunteers, although some start projects on their own with the best of intentions and undoubtedly praiseworthy motives. However, unfortunately, many volunteers lack first hand experience in the field and therefore are ill prepared to make a realistic assessment of their own abilities, purposes and limitations. Consequently, they can fail to address the real needs of their host communities or provide an inappropriate form of dentistry. Some basic questions therefore need to be raised in this context.

Who benefits from such volunteer efforts? The dentistvolunteer may well benefit from the service rendered because his or her efforts are rewarded with immense satisfaction and increased esteem after returning home. However, the danger is that the population as a whole may not benefit from these projects in the long run because the health care services offered are merely temporary and not structurally sustainable. In particular, the traditional curative approach is too costly to be taken over by local health care systems and fails to address the needs of the majority of deprived communities.

A further disadvantage is that the indigenous community very often ends up regarding the local health care system, where one already exists, as being inferior in quality. This substantially undermines the community's efforts to find their own solutions to the existing problems. Moreover, such projects devalue the status of local health workers who find themselves unable to meet the community's expectations once the visiting volunteers, who raised such high hopes, have left the project. This may have a negative effect by creating dependency instead of empowerment and leaving communities with the feeling that local political choices are useless, or without impact, because resources of the local health care system are in most cases lower than those of the intervening NGO.

Certainly, in areas where there is absolutely no form of oral care the provision of basic emergency care will always be a great priority. However, the ultimate goal should not be to treat as many patients as possible within the fairly short period of the volunteer's stay, but to make a contribution towards the training of local health workers who can continue with the care after the departure of the volunteer.

Despite these possible serious negative impacts there remains an essential and important role for volunteers and dental NGOs in international oral health. The framework of the WHOendorsed Basic Package of Oral Care can provide guidance and opportunities for a change towards appropriate, evidence-based interventions and community support with the potential for sustained improvements of oral health. These include:

- oral urgent treatment: the relief of oral pain, first aid for oral infections and dento-alveolar trauma and referral of complicated cases.

- affordable fluoride toothpaste: which is an efficient tool to create a healthy and clean oral environment. The WHO states that fluoride toothpaste is one of the most important delivery systems for fluoride and the availability and affordability of an effective fluoride toothpaste is essential to every preventive programme.

- atraumatic restorative treatment: the approach which involves no dental drill, plumbed water or electricity. For dentinal caries, it consists of manual cleaning of cavities using hand instruments. The cavities and adjacent fissures are filled with an adhesive, fluoride-releasing restorative material, usually an auto-cured glass ionomer.

A reorientation of dental NGOs and volunteers is needed in order to increase the impact on international oral health. Critical discussions, honest evaluation and organisational change are difficult tasks for any organisation, and possibly even more so for value-driven, non-profit organisations. Oral health has been recognised as a basic human right and the overall guiding principle should be the achievement of optimal oral health for all. NGOs and their volunteers can be important contributors to this aim if they choose appropriate interventions and activities.

Dr Habib Benzian
Development \&t Public Health Manager, FDI World Dental
Federation, France
Prof Wim van Palenstein Helderman
WHO Collaborating Centre, Nijmegen, The Netherlands

doi: 10.1038/sj.bdj.4814133 